\title{
Ironing Out the Pathogenesis of Acute Kidney Injury
}

\author{
Sangeeta Hingorani, MD, \\ Seattle Children's Hospital, Seattle, Washington \\ Bruce A. Molitoris, MD, and \\ Indiana University School of Medicine, Indianapolis, Indiana \\ Jonathan Himmelfarb, MD \\ University of Washington School of Medicine, Seattle, Washington
}

\begin{abstract}
Acute kidney injury (AKI) is a serious and common complication with a reported incidence varying from 19 to 70 per 1,000 hospitalized patients. Despite recent advances in clinical care, the mortality associated with AKI remains high, ranging from $20 \%$ to $60 \%$ in hospitalized patients. ${ }^{1}$ Moreover, recent data emphasize that even in survivors, recovery of kidney function is often incomplete, and chronic kidney disease and even end-stage renal disease may ensue. 2
\end{abstract}

How can the outcomes in AKI be improved? An important initial step would be to develop better tools for identification and surveillance of at-risk patients and prognosis in the disease evolution. ${ }^{3}$ Current definitions of AKI rely on a change in serum creatinine as a glomerular filtration rate marker. However changes in creatinine, if not in equilibrium, cannot be used to accurately monitor kidney function. Even in the steady state, creatinine has limitations as a filtration marker in patients with alterations in creatinine generation, such as malnutrition, muscle wasting, hypercatabolism, cancer, elderly age, and those in whom third-space fluid accumulation and vigorous volume resuscitation results in dilution of the creatinine pool. ${ }^{4-7}$ Thus, the field of AKI is ripe for the development of new biomarkers that identify at-risk patients, and major efforts to accomplish this are well underway. However, AKI is a complex and heterogeneous process and the identification of biomarkers should not be limited to initial injury alone but should include markers of risk, injury propagation, and resolution of injury. In fact, it can be argued that markers of early resolution will be equally as important as markers of initial injury. Identifying markers of risk, injury, protection, and repair in human studies may also help us to better understand the pathogenesis of AKI, thereby informing future therapeutic efforts.

In this issue of American Journal of Kidney Diseases, Ho et al ${ }^{8}$ apply proteomics to analysis of urine for biomarker discovery in a prospective cohort study of individuals undergoing cardiopulmonary bypass surgery. There were several notable findings in the study. First, regardless of whether or not AKI developed, all subjects had early evidence of tubular dysfunction and stress as demonstrated by early $\beta_{2}$-microglobulinuria. Systemic markers of inflammation, such as the proinflammatory cytokine IL- 6 and several chemokines, were also elevated in both groups at each of the time points measured. Second, in those patients who

\footnotetext{
Address correspondence to Jonathan Himmelfarb, MD, Division of Nephrology, University of Washington School of Medicine, Seattle, WA. E-mail: E-mail: himmej@u.washington.edu.

Publisher's Disclaimer: This is a PDF file of an unedited manuscript that has been accepted for publication. As a service to our customers we are providing this early version of the manuscript. The manuscript will undergo copyediting, typesetting, and review of the resulting proof before it is published in its final citable form. Please note that during the production process errors may be discovered which could affect the content, and all legal disclaimers that apply to the journal pertain.
} 
went on to develop AKI, the urinary proteome became more complex, suggesting either a second phase of injury or progression of injury. In these individuals, $\alpha_{1}$-microglobulin and neutrophil gelatinase-associated lipocalin (NGAL) were identified as early as 1 hour into the bypass procedure and remained elevated at postoperative days 3 to 5 in patients with AKI compared with those patients who did not develop AKI. Third, and perhaps most interesting, proteomic analysis identified 2 high-intensity peaks whose appearance postoperatively was associated with lack of development of AKI. One of these peaks was subsequently determined to be hepcidin 25 , which was preferentially found in the urine on postoperative day 1 of patients who did not go on to develop AKI. Since hepcidin is a master regulator of iron homeostasis, these data once again invoke the importance of free iron in the pathogenesis of ischemic and toxic AKI.

Two decades ago, seminal studies suggested that free iron plays a role in models of ischemic and toxic AKI. In a rat model of gentamicin toxicity, rats treated with a hydroxyl radical scavenger or an iron chelator (desferoxamine) had significantly lower serum urea nitrogen levels and improved histology compared with untreated rats, suggesting a role for iron and generation of hydroxyl radicals in toxic AKI. ${ }^{9}$ Similarly, in a rat model of ischemia-reperfusion injury induced by clamping the renal artery, pretreatment with desferoxamine can prevent the development of AKI. In that study, urinary levels of free iron increased 10- to-20 fold during reperfusion with no change in the plasma levels. These studies each support a role for iron in mediating AKI through generation of oxygen free radicals and suggest that this injury takes place in the urinary space. ${ }^{10}$ Human studies have demonstrated excess iron accumulation in proximal tubule lysosomes in biopsies of patients with AKI. ${ }^{11}$

Hepcidin 25, the 25-amino acid bioactive form of the peptide hormone made in the liver, regulates iron homeostasis via downregulation of ferroportin, an iron exporter located in hepatocytes, enterocytes, and macrophages. Hepcidin production is suppressed by anemia and hypoxia and induced by infection and inflammation. ${ }^{12}$ In the kidney, hepcidin is strongly expressed in the thick ascending limb of the cortex and the connecting tubules. Moderate expression is found in the collecting ducts and thick ascending limb of the medulla. ${ }^{13}$ One could postulate that the upregulation of hepcidin in these segments of the nephron after renal ischemia leads to a downregulation of the ferroportin exporter, preventing the further release of free iron into tissues and resulting perpetuation of tubular injury.

It is of considerable interest that, in the study by Ho et al, urinary NGAL and hepcidin, both proteins that bind or regulate iron, had opposing predictive effects for the development of AKI. It may turn out to be the ratio of NGAL to hepcidin, rather than each marker in isolation, that best predicts the development, or lack thereof, of AKI. NGAL, which binds siderophore iron, is expressed in the kidney, where it may be localized in the loop of Henle and collecting ducts. However, circulating NGAL released from inflammatory cells probably accounts for most of the NGAL found in the proximal tubule and presumably in the urine in the setting of kidney injury. ${ }^{14}$ To further complicate the picture, it has recently been reported that bone morphogenetic protein (BMP) signaling, with hemojuvelin as a coreceptor, regulates the expression of hepcidin in the liver. ${ }^{15}$ Since BMP signaling in the kidney may be important in reparative processes, it is possible that if this pathway is operative in the ischemic kidney, it may account for the observed association of increased urinary hepcidin with protection from AKI. The kidney is also the mouse tissue where iron regulatory protein 1 (IRP-1) is most highly expressed and is localized to the proximal tubule 16,17 and the role of multiple participants in kidney iron regulation still needs to be carefully examined for their relevance in the pathogenesis of AKI.

Although of great interest and potential importance, there are a number of concerns with the study by Ho et al that must be addressed in future research. First, the SELDI-TOF (surface- 
enhanced laser desorption/ionization time-of-flight) mass spectrometric proteomics platform used in this study is largely qualitative and not ideal for definitive quantitation or even structural identification of analytes. Second, validation of the findings in other cohorts is necessary, given the high potential for false detection rates in proteomics studies. New studies examining the hypothesis that hepcidin is an important protective molecule in renal ischemic/toxic injury should be facilitated now that a serum enzyme-linked immunosorbent assay for hepcidin has been developed and validated in healthy volunteers. ${ }^{18}$

\section{Acknowledgments}

Financial Disclosure: Dr Molitoris reports the following relationships: Quark Pharmaceuticals and Eli Lilly \& Co: member of the Advisory Board and recipient of research grants; Astra Zeneca: member of the Advisory Board; FAST Diagnostics: Medical Director, member of the Board of Directors, partial owner. The other authors report that they have no relevant financial itnerests to disclose.

\section{References}

1. Waikar SS, Liu KD, Chertow GM. Diagnosis, epidemiology and outcomes of acute kidney injury. Clin J Am Soc Nephrol 2008;3:844-861. [PubMed: 18337550]

2. Ishani A, Xue JL, Himmelfarb J, et al. Acute kidney injury increases risk of ESRD among elderly. J Am Soc Nephrol. 2008[epub ahead of print]

3. Molitoris BA, Melnikov VY, Okusa MD, Himmelfarb J. Technology Insight: biomarker development in acute kidney injury-what can we anticipate? Nat Clin Pract Nephrol 2008;4:154-165. [PubMed: 18227821]

4. Beddhu S, Samore MH, Roberts MS, Stoddard GJ, Pappas LM, Cheung AK. Creatinine production, nutrition, and glomerular filtration rate estimation. J Am Soc Nephrol 2003;14:1000-1005. [PubMed: 12660334]

5. Ross EA, Wilkinson A, Hawkins RA, Danovitch GM. The plasma creatinine concentration is not an accurate reflection of the glomerular filtration rate in stable renal transplant patients receiving cyclosporine. Am J Kidney Dis 1987;10:113-117. [PubMed: 3300293]

6. Levey AS, Bosch JP, Lewis JB, Greene T, Rogers N, Roth D. A more accurate method to estimate glomerular filtration rate from serum creatinine: a new prediction equation. Modification of Diet in Renal Disease Study Group. Ann Intern Med 1999;130:461-470. [PubMed: 10075613]

7. Fliser D, Franek E, Joest M, Block S, Mutschler E, Ritz E. Renal function in the elderly: Impact of hypertension and cardiac function. Kidney Int 1997;51:1196-1204. [PubMed: 9083286]

8. Ho J, Lucy M, Krokhin O, Hayglass K, et al. Mass spectrometry-based protemic analysis of urine in acute kidney injury following cardiopulmonary bypass: A nested case-control study. Am J Kidney Dis 2009;53:•••-•••.

9. Walker PD, Shah SV. Evidence suggesting a role for hydroxyl radical in gentamicin-induced acute renal failure in rats. J Clin Invest 1988;81:334-341. [PubMed: 3123518]

10. Paller MS, Hedlund BE. Role of iron in postischemic renal injury in the rat. Kidney Int 1988;34:474480. [PubMed: 3143849]

11. Nankivell BJ, Boadle RA, Harris DC. Iron accumulation in human chronic renal disease. Am J Kidney Dis 1992;20:580-584. [PubMed: 1462986]

12. Nemeth E, Ganz T. Regulation of iron metabolism by hepcidin. Annual review of nutrition 2006;26:323-342.

13. Kulaksiz H, Theilig F, Bachmann S, et al. The iron-regulatory peptide hormone hepcidin: expression and cellular localization in the mammalian kidney. J Endocrinol 2005;184:361-370. [PubMed: 15684344]

14. Schmidt-Ott KM, Mori K, Li JY, et al. Dual action of neutrophil gelatinase-associated lipocalin. J Am Soc Nephrol 2007;18:407-413. [PubMed: 17229907]

15. Babitt JL, Huang FW, Wrighting DM, et al. Bone morphogenetic protein signaling by hemojuvelin regulates hepcidin expression. Nat Genet 2006;38:531-539. [PubMed: 16604073] 
16. Meyron-Holtz EG, Ghosh MC, Iwai K, et al. Genetic ablations of iron regulatory proteins 1 and 2 reveal why iron regulatory protein 2 dominates iron homeostasis. EMBO J 2004;23:386-395. [PubMed: 14726953]

17. Zhang D, Meyron-Holtz E, Rouault TA. Renal iron metabolism: transferrin iron delivery and the role of iron regulatory proteins. J Am Soc Nephrol 2007;18:401-406. [PubMed: 17229905]

18. Ganz T, Olbina G, Girelli D, Nemeth E, Westerman M. Immunoassay for human serum hepcidin. Blood 2008;112:4292-4297. [PubMed: 18689548] 